\title{
PENGEMBANGAN KAWASAN PEDESAAN MELALUI INTRODUKSI TEKNOLOGI BIOGAS SNI 7826: 2012 DI DIY SEBAGAI MODEL INDUSTRI KREATIF BERBASIS SYARIAH
}

\author{
Meidi Syaflan ${ }^{1}$, Ngatirah $^{2}$, Sunardi ${ }^{3}$, dan Nadime Lasykar Muhammad ${ }^{4}$ \\ ${ }^{1,2,3,4}$ Fakultas Teknolog Pertanian, Institut Pertanian Stiper Yogyakarta
}

Email :

\begin{abstract}
ABSTRAK
Upaya merubah wajah pedesaan menjadi kawasan pengembangan ekonomi industry kreatif dengan mengintroduksi teknologi biogas sebagai penghasil energy bersih, murah dan berkelanjutan dibeberapa desa di kawasan DIY telah menunjukkan hasil awal yang cukup menggembirakan. Pembangunan tersebut berhasil menyediakan rumah tangga pemilik biogas rumah (biru) tersebut kelimpahan energy dalam bentuk biogas (gas metan) dan Bioslurry yang dapat dimanfaatkan untuk mendukung usaha pertanian dalam arti luas. Meskipun demikian masih banyak kendala yang dihadapi untuk mengoptimalkan potensi sumber daya ekonomi pedesaan untuk menjadi kawasan pengembangan ekonomi industry kreatif terutama yang berkaitan dengan kebijakan dan regulasi pemerintah yang cenderung mematikan modal sosial yang berakar dimasyarakat. Untuk mengeliminir hal tersebut selain perlu pendekatan baru dalam pelaksanaan pembangunan pedesaan oleh pemerintah juga dianggap perlu untuk menumbuhkan kelembagaan yang kuat dan berakar dimasyarakat untuk memayungi aktivitas tersebut, organisasi ekonomi berbasis syariah seperti BMT dapat menjadi pilihan untuk kepentingan tersebut.
\end{abstract}

Kata kunci: Biogas; bioslurry; modal sosial dan BMT

\section{ABSTRACT}

Efforts to change the face of rural areas into areas of economic development of creative industry by introducing energy-producing biogas as a clean, cheap and sustainable DIY in several villages in the region have shown initial results were quite encouraging. The successful development of domestic supply biogas owner of the house (blue) is an abundance of energy in the form of biogas (methane) and Bio-slurry that can be used to support agriculture in the broad sense. Nevertheless there are still many obstacles faced to optimize resource potential of the rural economy to become a regional economic development of the creative industry, especially with regard to government policies and regulations are likely to turn off social capital that is rooted in the community. To eliminate that in addition to the new approach in the implementation of rural development by the government also considered necessary to foster strong institutions and deeply rooted in the community for such activities umbrella, sharia-based economic organization like BMT may be an option for this purpose.

Keywords: Biogas; bio-slurry; social capital and BMT 


\section{PENDAHULUAN}

Posisi strategis pedesaan sudah disadari sejak lama dan menjadi perhatian utama pemerintah karena sebagian besar potensi kehidupan ekonomi dan sumber daya pembangunan berada di kawasan tersebut. Beragam program yang dilakukan dengan pelbagai nama dan kegiatan umumnya bermuara pada dua kegiatan pokok yaitu pembangunan fisik dan pemberdayaan sosial ekonomi masyarakat pedesaan. Kegiatan pembangunan fisik relatif berhasil jika dibandingkan dengan kegiatan ekonomi yang embirionya telah dirancang satu paket dengan pembangunan fisik dengan bermacam nama seperti unit pengelola keuangan (UPK) untuk mengoptimalkan pembangunan fisik tadi untuk kegiatan ekonomi. Dominansi kekuasaan aparat desa telah memarjinalkan potensi desa sehingga desa identik dengan kemiskinan, keterbelakangan akibat dari lemahnya partisipasi masyarakat.

Peningkatan partisipasi masyarakat pedesaan melalui tahapan pemberdayaan secara bertahap mulai dari rekruitmen pelaku dan pembentukan organisasi pelaksana serta proses perencanaan serta pelaksanaan pembangunan secara mantap berhasil mendapatkan dukungan partisipasi masyarakat jika dihitung secara nominal besarannya mencapai sama besar dengan anggaran program. Selain itu karena rencana pembanguna fisik tersebut dilakukan secara partisipatif maka para pemanfaat bersedia untuk mengeluarkan dana untuk pemeliharaan bangunan fisik tersebut untuk menunjang kegiatan perekonomian mereka (Meidi Syaflan., 2009).

Model pembagunan pedesaan melalui pemberian alokasi dana desa dan anggaran dana desa memberikan harapan baru bagi pengembangan desa sebagai kawasan pertumbuhan ekonomi baru karena setiap rupiah anggaran yang dikucurkan harus dapat dipertanggungjawabkan secara administratif maupun hukum. Selain itu model pembangunan tersebut diharapkan dapat memperkuat dan menumbuhkan kembali modal sosial (social capital, SC) yang mulai melemah akibat dari kinerja politik dan aksi pemerintah. Menguat dan tumbuhnya SC berupa sikap proaktif, kompak, rukun, solidaritas sosial kuat yang merupakan kearifan lokal bangsa Indonesia mampu menggeser perilaku pasif dan ketergantungan kepada pemerintah karena model pembangunan tersebut mirip dengan model participatory budgeting (PB) yang mengedepankan: pemberdayaan, tranparansi,akuntabilitas, berkelanjutan dan partisipasi (Meidi Syaflan.,2009).

Kawasan pedesaan identik denganusaha pertanian sehingga pengembangan kawasan pedesaan tidak dapat dipisahkan dari pengembangan sektor pertanian.

Permasalahannya adalah konsep seperti apakah yang harus diimplementasikan dalam pembangunan kawasan pedesaan agar kawasan tersebut lambat laun dapat melepaskan diri dari konotasi negatif sebagai kawasan tertinggal menjadi pusat pertumbuhan ekonomi baru sebagaimana Thailand dengan konsep one village one product (OVOP) dan semboyan Semaul Undong di Korea. Setelah melakukan beberapa kajian dan berdasarkan pengalaman pengembangan pedesaan khususnya melalui program peningkatan pendapatan petani melalui inovasi (P4MI) maka sejak tahun 2013 dimulailah kegiatan pembangunan industry kreatif di pedesaan dengan mengintroduksi teknologi biogas sebagai pengungkit perekonomiannya.

Teknologi Biogas sudah cukup lama di kembangkan Indonesia mulai yang bersifat uji coba pada wilayah terbatas sampai dengan gerakan atau program yang dilakukan pada 
kawasan yang cukup luas. Jenis yang dikembangkanpun cukup beragam mulai dari yang sederhana menggunakan drum aspal, dari fiberglass maupun menggunakan kubah tetap dengan material dari beton. Teknologi biogas relatif sederhana dan mudah dikembangkan menggunakan material yang tersedia di kawasan pedesaan untuk membangun biodigester sebagai penghasil gas metan.

Pada wilayah yang memiliki jumlah ternak sapi tinggi, teknologi ini dapat menjadi alternatif bagi pemenuhan kebutuhan energi keluarga, kebersihan lingkungan dan kontribusi bagi pengurangan emisi gas karbon. Selain itu limbah dari biodigester adalah produk organik yang telah terfermentasi secara anaerob sehingga dapat digunakan sebagai pupuk karena kandungan senyawa makro, mikro maupun mikrobia yang terdapat dalam limbah yang disebut dengan bioslurry.Kemudahan teknologi dan konstruksi biodigester serta aneka manfaat yang dapat diraih baik yang bersifat ekonomis maupun ekologis, ternyata pengembangannya tidak dapat berlangsung secara mandiri serta berkelanjutan. Bahkan kecenderungan pertumbuhan pembangunan biogas di Indonesia relatif tertinggal di bandingkan dengan Negara lain seperti Nepal, Bangladesh, Filifina, Pakistan, India dan Tiongkok di kawasan Asia maupun beberapa Negara dikawasan Afrika dan Amerika Latin.

Secara Umum, biogas dapat didefinisikan sebagai gas yang mudah terbakar yang dihasilkan dari proses fermentasi anaerobic dari material organik yang dilakukan oleh bakteri metanogenic. Proses perubahan material organic menjadi gas tersebut terjadi dalam suatu ruangan yang didisain khusus agar dapat berlangsung secara simultan dengan mempertimbangkan kseimbangan antara pasokan bahan baku, gas yang terbentuk dan bioslurry yang dihasilkan. Ruangan khusus tersebut dinamakan biodigester, model biru memiliki beberapa ukuran mulai dari 4,6,8,10 dan 12 m3. Masingmasing ukuran disesuaikan dengan ketersediaan pasokan bahan baku rutin harian., jumlah anggota keluarga yang memakai gas serta rencana volume pemanfaatan bioslurry untuk satuan waktu tertentu. Secara skematis rancangan biogas model biru disajikan pada gambar 1 .

Upaya menjamin keberhasilan introduksi teknologi biogas tersebut dilakukan dengan terlebih dahulu melakukan pemahaman terhadap keberlangsungan program tersebut di DIYdan mendapatkan kesimpulan antara lain: sebagian besar program tersebut gagal dikarenakan sistem pembangunannya yang menggunakan pendekatan keproyekan sehingga bangunan fisik tidak memenuhi persyaratan penghasil gas dang meninggalkan prinsip partisipasi masyarakat (Meidi Syaflan.,Ngatirah dan Nadime Lasykar Muhammad.,2015). Temuan lain adalah pendekatan yang dilakukan oleh pemerintah sangat parsial karena hanya melihat program biogas sekedar sebagai penghasil energy tanpa mempertimbangkan potensi biogas lainnya secara komprehensif untuk mendukung sector pertanian, perkebunan, peternakan serta perikanan (Meidi Syaflan,..Ngatirah dan Sunardi, 2014).

Introduksi teknologi biogas di Indonesia perlu menggunakan pendekatan baru jika pengembangan program ini diharapkan dapat berlangsung secara berkelanjutan. Perlu pergeseran perspektif pembangunan yang dilakukan oleh pemerintah dari yang masih berorientasi pada output menjadi orientasi pada outcome, dari pendekatan sektoral parsial menjadi pendekatan integratif. Perubahan mekanisme keproyekan dalam penentuan rekanan kerja perlu melibatkan secara intens masyarakat pemanfaat dan untuk pembangunan biodigester karena memerlukan biaya yang relatif kecil jika dilihat 
dari total anggaran yang masuk kedesa maka mekanisme pengadaan yang berlangsung saat ini tidak efektif mendukung keberlanjutan program pengembangan biogas Indonesia. Salah satu pendekatan yang dapat digunakan adalah mekanisme penganggaran partisipatif.

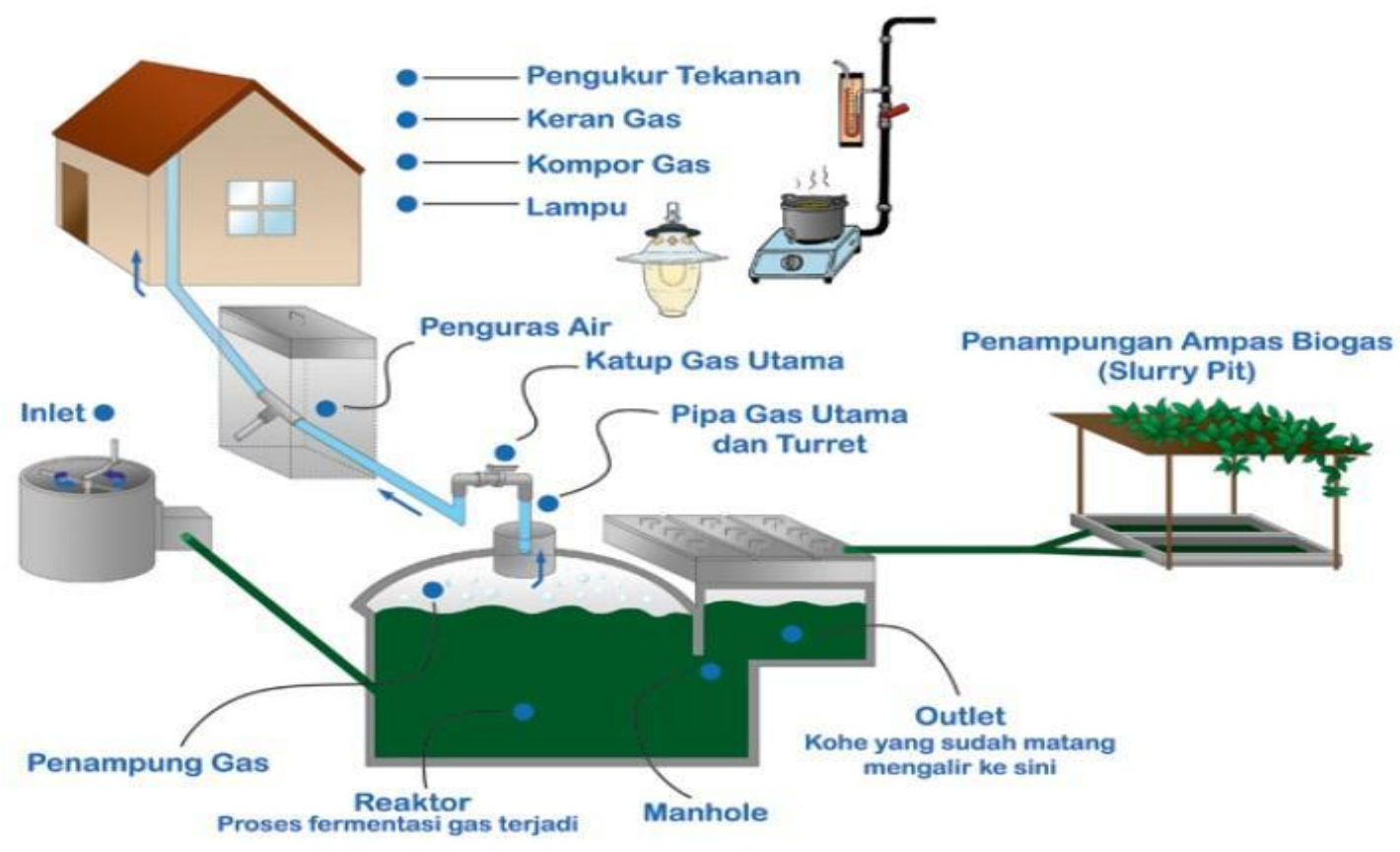

Gambar 1. Skema biogas model biru SNI 7826:2012

Konstruksi biodigester model BIRU adalah sebagai berikut :Kubah Tetap (Fixed Dome), menggunakan material lokal, seperti bata/batako, semen, pasir, kerikil. Kelebihan konstruksi ini adalah biaya lebih murah dari tipe fiberglass, membangun dapat menggunakan tenaga local yang dilatih, perawatan dan, operasional mudah serta murah, kecepatan memasak setarakompor LPG dan tahan lama ( di Nepal Negara asal konstruksi biru sudah ada yang berumur 30 tahun). Sebagian besar bangunan berada dibawah permukaan tanah sehingga menggunakan lahan yang relatif sempit,pada beberapa pengguna biodigester di bangun dibawah kandang sapi. 


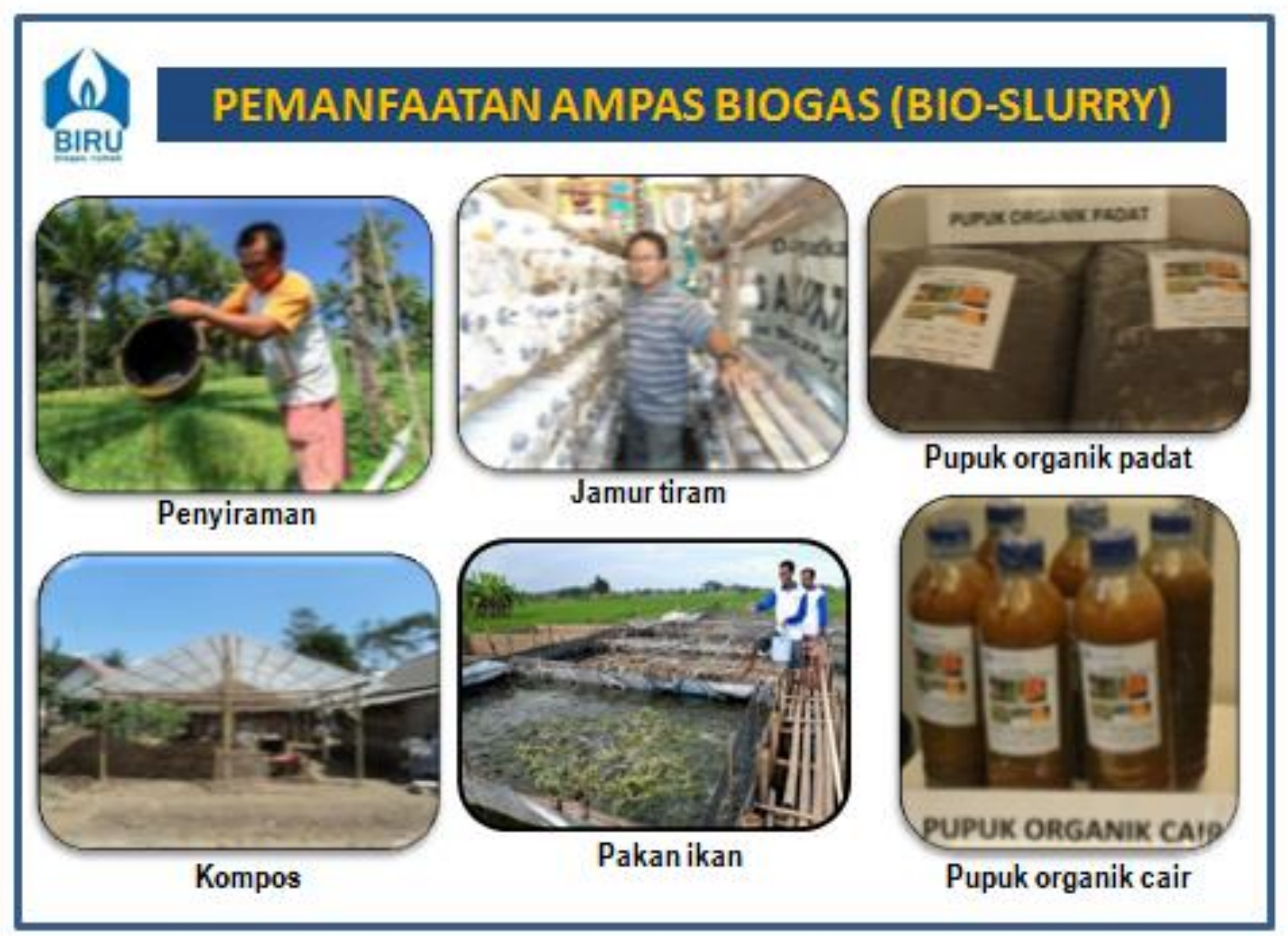

\section{METODE}

Pengembangan biodigester SNI
7826:2012 dengan metode PB dan
pengembangan industry kreatif berbasis biogas
dan bioslurry serta penumbuhan lembaga
keuangan mikro syariah yang berakar di
masyarakat sebagai penyangga keuangan
kawasan industry pedesaan.

\section{HASIL DAN PEMBAHASAN}

Pengembangan biodigester biogas tipe ini di daerah Istimewa Yogyakarta (DIY) sejak tahun 2013 oleh Pusat pengembangan biogas dan bioslurry Indonesia (Indonesia biogas and bios/urry development centre, IB2DC) jurusan Teknologi Hasil Pertanian, Fakultas Teknologi Pertanian Instiper Yogyakarta berhasil membangun 200 unit dan $98 \%$ berfungsi baik (data sampai dengan bulan Agustus 2015). Pembangunan biodigester dapat dilakukan dengan cara menyebar maupun terkonsentrasi, pada wilayah dengan kepadatan populasi ternak tinggi diupayakan pendekatan kelompok agar terkonsentrasi. Beberapa wilayah pengembangan terkonsentrasi antara lain di Desa Donotirto sebanyak 27 unit dan desa Parangtritis 6 unit dikecamatan Kretek., Desa Wonolelo 24 unit di kecamatan Pleret dan Dusun Nawungan Desa Selopamioro, kecamatan Imogiri 15 unit untuk Kabupaten Bantul. Di kabupaten Sleman di dukuh Randu Desa Hargobinangun sebanyak 15 unit dan dukuh Kemiri Desa Purwobinangun sebanyak 8 unit seluruhnya di kecamatan Pakem dan Dusun Candisari Desa Wukirharjo kecamatan Prambanan.

Bioslurry sebagian besar baru dimanfaatkan secara alamiah untuk pengganti atau pelengkap pupuk untuk aneka tanaman seperti padi, jagung kedelai, Lombok, tomat 
dan beberapa komoditas perkebunan seperti tebu dan tembakau, hanya beberapa petani yang memulai untuk mengolah lebih lanjut bioslurry menjadi pupuk cair maupun biopestisida. Fermentasi lanjutan bioslurry menggunakan beberapa jenis mikrobia dapat meningkatkan kandungan nitrogen dan memamcu pertumbuhan tanaman yang diuji coba (Meidi Syaflan., Ngatirah dan Yusuf Wibowo., 2013). Meskipun potensial masih cukup banyak bioslurry yang belum termanfaatkan secara optimal diakibatkan kepemilikan lahan yang sempit sedangkan produksinya relative stabil mencapai 65 liter/ hari/biodigester ukuran 6 m3 (Meidi Syaflan., Nadim Lasykar Muhammad dan Irwan,.2014). upaya memotivasi para pengguna biogas untuk mau berbagi dengan petani lain secara personal belum memberikan hasil yang maksimal karena masih ada keengganan para pihak untuk saling berbagi dan mengimbangi memberi manfaat secara mutualistic. Hal yang sama juga terjadi pada pemanfaatan gas metan (LPG) hasil dari biodigester mereka yang menunjukkan terjadinya kelebihan produksi gas dibandingkan dengan pemanfaatan untuk pemenuhan kebutuhan sehari- hari. Aktivitas memasak untuk kebutuhan rumah tangga pada pagi hari selama 2 jam, siang hari 1 jam dan sore serta malam hari sekitar 2 jam sedangkan produksinya dapat bertahan 8-11jam jika dihidupkan terus menerus (Meidi Syaflan., 2015). Anjuran untuk berbagi kepada kerabat atau tetangga yang belum memiliki instalasi biogas serta menumbuhkan home industry untuk memanfaatkan biogas dan bioslurry belum memperlihatkan titik keberhasilan.

Keberhasilan pembangunan biogas yang dilakukan dengan pendekatan baru tersebut antara lain disebabkan oleh pendekatan perencanaan kolektif dan kooperatif sehingga menghasilkan perencanaan yang efektif
(Bencik dan Bognar., 2007) diakibatkan oleh keikutsertaan mereka dalam pengambilan keputusan sehingga menumbuhkan partisipasi (Sobol,. 2008). Implementasi teknologi biogas dengan pendekatan baru tersebut memberikan harapan baru bagi pengembangan industry kawasan pedesaan manakal pemerintah secara konsinten menerapkan prinsip partisipatif dalam memanfaatkan alokasi dana desa maupun anggaran dana desa. Optimalisasi potensi biogas dan bioslurry beserta pemanfaatan anggaran dana untuk pedesaan tersebut akan semakin tinggi tatkala badan usaha milik desa (Bumdes) mampu menaungi aktifitas tersebut diatas berdasarkan prinsip- prinsip ekonomi secara inovatif dan kreatif. Memperhatikan kearifan local dan potensi sumberdaya riel pedesaan dan pendekatan SC maka organisasi dan kelembagaan yang menaungi aktivitas ekonomi kreatif tersebut idealnya berbasis syariah. Untuk mewujudkan hal tersebut dibutuhkan kawasan yang dapat dijadikan model pengembangan kawasan pedesaan Indonesia, DIY adalah salah satu kawasan tepat untuk menjadi model karena keberhasilannya secara mandiri dan berakar dalam menumbuhkembangkan lembaga keuangan mikro syariah baitul maal watamwil di Indonesia (Meidi Syaflan., 2013).

\section{KESIMPULAN}

Keberhasilan pembangunan biodigester oleh Jurusan THP Fateta Instiper di kawasan pedesaan di DIY dengan melakukan perubahan pendekatan yang mengedepankan panrtisipasi masyarakat memberikan harapan baru untuk tumbuh dan berkembangnya perekonomian pedesaan dengan perspektif baru. Memanfaatkan hasil penelitian secara terintegrasi baik dilaboratorium maupun di tingkat masyarakat diharapkan dapat merubah wajah kawasan pedesaan yang konotasinya negative menjadi kawasan industri kreatif 
berbasiskan pada sumber daya local untuk menghela pertumbuhan ekonomi dan peningkatan kesejahteraan. Untuk menjamin keberlangsungannya maka perlu penumbuhan kelembagaan yang berakar kuat dimasyarakat untuk menaungi aktivitas ekonomi tersebut dan berdasarkan kajian ilmiah maka lembaga terseb

ut selayaknya berbasis dan menggunakan prinsip- prinsip syariah. Jika model kelembagan tersebut berhasil diwujudkan dan diintegrasikan dengan introduksi teknologi biogas maka model industry kawasan pedesaan tersebut dapat di diseminasikan untuk membangun pedesaan di Indonesia.

\section{DAFTAR PUSTAKA}

Meidi Syaflan, Ngatirah, dan Sunardi. 2014. MENUJU KEBIJAKAN YANG KOMPREHENSIF, UPAYA OPTIMALISASI PROGRAM PENGEMBANGAN BIOGAS DI INDONESIA (Studi Kasus Pengembangan Biodigester Model Biogas Rumah (BIRU) SNI 7826:2012 di Daerah Istimewa Yogyakarta). Seminar Nasional Sinergi Pangan, pakan dan energi terbarukam, Eastparc Hotel Yogyakarta 21-23 Oktober 2014.

Meidi Syaflan, Ngatirah, dan Nadime LM, 201 ANALISIS KEBERLANJUTAN PROGRAM PENGEMBANGAN BIOGAS INDONESIA, STUDI KASUS DI DAERAH ISTIMEWA YOGYAKARTA. Universitas Trunojoyo, 6-7 Okttober 2015.

Meidi Syaflan, Ngatirah dan Yusuf Wibisono. 2013. Pengaruh penambahan bioslurry pada pembuatan pupuk cari dari limbah kelapa sawit. Skripsi Teknologi hasil Pertanian Fateta Instiper.

Meidi Syaflan. 2009. Membangun desa menggerus kemiskinan. Yayasan Agibisnis Jakarta dan Departemen
Pertanian RI. Laporan akhir Program P4MI.ISBN 979-3381-99-2.

Meidi Syaflan.2011. Membangun gerakan BMT Indonesia. Sebuah bunga rampai. Lembaga Ombudsman Swasta DIY. ISBN 978-602-99355-3-0.

Meidi Syaflan. 2013. Tipologi Governance Baitul Maal WatTamwil (BMT) di DIY. Disertasi Doktor Program Doktor Ekonomi Fakultas Ekonomi UII.

Meidi Syaflan, Nadime L. Muhammad dan Irwan. 2015. Kajian Produktivitas dan Pemanfaatan Biodigestes Biru SNI 7826:2012 di DIY.(belum diterbitkan) 